


\section{On Zero Waste in Art and the Reproduction of Capitalism 'with Human Face'}

\section{Nadine Schneiderbauer}

In the following essay, I will not only present the artist Lavinia Lanner and her art work o.T. (if tomorrow never comes), which is to be shown at the exhibition Artist's Waste, Wasted Artist in September 2017, but also focus on how capitalism shapes contemporary art and what the role of 'zero-waste' in the art-world could be or already is. In the end, there will be a statement from Lavinia Lanner herself, about her credo of zero waste.

\section{Art under Capitalism and the Role of Zero-waste}

Lavinia Lanner was born in 1985 and grew up bilingual, speaking German and Italian, in Abtenau near Salzburg. She later decided to study art in Vienna at the Academy of Fine Arts, as well as translation studies at the University of Vienna. For her paintings, she mainly (only) uses pencils with the thickness of 3B. Her work is usually abstract, approximating redrawn brushstrokes. Before she starts a painting, she creates sketches and layouts. For this part, she has no concept and does not know where the artwork is headed. She is working with different materials, like paint brushes, clothes and so on. After that, she picks out one sketch, or just a detail from it, and begins to redraw it with her pencil. Once she has started her painting she knows exactly how it should be and has a clear concept. From this time onwards, nothing is left to chance. Normally, once started, an artwork of hers is going to be finished, except the following one, which she started in 2013 during an artist-in-residence-stay. She did not like it very much and decided not to finish it. Until 2017, her artwork was kept in storage. Following my suggestion to be part of this exhibition, she kept looking through her archive and finished artwork only for the project Artists' Waste, Wasted Artists. For her, it is now an 'inbetweener', - normally she would sell this kind of a drawing for about $800 €$, but when it comes to this one, she is not quite sure if she should charge the same price. Lanner's credo is zero waste - a new trend becoming more and more popular - even in the art world, or especially in the art world, where this new trend has been gaining popularity, shaping the work of many artists. Everything can be reused and upcycled, what is kept in storage may be sold later (often for a higher price). Is the upcycling and reusing process only about the environment and nature? Or is it rather about following the mainstream and making a profit? Can the artist put a price tag on his/her re-used work with the same amount as his/her other paintings? Or should it be less, because before it was kind of a 'waste-product'? Or the very opposite, because of reusing it - the artist gave it some new value?

The philosopher and cultural theorist, Slavoj Žižek discussed in his book First as Tragedy, Then as a Farce a similar trend towards eco-capitalism, moral capitalism or capitalism with a human face, which aims to ideologically cover up the and present itself as the very solution to the problems and damage it creates (Žižek 2009). Capitalism with human face pushes the ideology that capitalism itself can contribute to a better world, where the environment is treated with respect, and where some of your money goes to a charity project if you buy one cup of coffee. If you buy something, you are already doing something for the environment. Like Starbucks for example: You are not just buying a simple cup of coffee, no! You do so much more, because the company 
purchases more Fair Trade coffee than any other company and makes sure that the hardworking farmers earn a fair price for their hard work (Žižek 2009). 'When you choose Starbucks, you are buying a cup of coffee from a company that cares. No wonder that it tastes good!' (Žižek 2009, 58) - morality and a feeling of ethical superiority are already built into the product, just another thing to consume. Žižek also mentions that people are more likely to buy organic food not because it is necessarily healthier, but because they feel like they are doing 'something meaningful, showing [...] capacity for care and [...] global awareness, participating in a collective project' (Žižek 2009, 59). But we must be aware that this ability to purchase good conscience is typically reserved only for the few on the top, for the global elites.

Embedded within capitalism today, is the idea that it can smoothly merge the antagonistic positions of being an altruistic pro-environmental person and a consumerby consuming more you can 'save the world', or else, have a cake and eat it too. Hence, although education may provide awareness of environmental and sustainability issues or worldwide exploitation of workers, it is nonetheless difficult to operate individually within the consumeristic culture or capitalism. The only thing we have left, if sufficiently privileged, is to feel pro-environment by buying a green car or recycle.This environmental awareness can be seen in the attempt of living a nearly 'zero-waste' life. Zero Waste Alliance International defines zero waste as: 'Zero Waste is a goal that is ethical, economical, efficient and visionary, to guide people in changing their lifestyles and practices to emulate sustainable natural cycles, where all discarded materials are designed to become resources for others to use.'

Reusing and upcycling has always been part of being an artist as it seems. Working with different materials and combining them to create something stunning. Art and waste may always have gone hand in hand and was it not Leonardo Da Vinci who said 'there is no such thing as waste' (Connett 2013)? Somebody's waste could be an artist's next sculpture element. Such a sculpture that could be sold for a good price, even though it was considered as waste before. Artists are giving these waste products a new value; they are transforming it into something special. Upcycling and reusing may not always be just about the environment or the nature, but following the new credo of the $21^{\text {st }}$ century 'zero waste', it is marketed as a 'little revolution or rebellion' against the consumer society and the capitalistic world. Helping the environment by (re-)using everything and selling it for a good price?! Is this not merely a perfect way to sustain the capitalistic world while having the feeling of working 'against' it. Lavinia Lanner is trying to live the credo of zero waste herself; this is her statement: 'In the everyday life, my credo is ,zero waste", but do my strict criteria for sustainability and prevention of waste also stretch into my artistic practice in the atelier? The answer is no, it must be no. The artistic process lives from trials and failures, from throwing away, repetition.'

Connett, Paul. 2013. The Zero Waste: Untrashing the Planet One Community at a Time, Chelsea Green Publishing.

Žižek, Slavoj. 2009. First as Tragedy, Then as Farce. London/New York. 